\title{
Synthesis and Cytotoxicity of Chalcones and 5-Deoxyflavonoids
}

\author{
Jing Zhang, ${ }^{1}$ Xin-Ling Fu, ${ }^{2}$ Nan Yang, ${ }^{1}$ and Qiu-An Wang ${ }^{1}$ \\ ${ }^{1}$ College of Chemistry and Chemical Engineering, Hunan University, Changsha 410082, China \\ ${ }^{2}$ Department of Basic Medical, Changsha Medical University, Changsha 410082, China
}

Correspondence should be addressed to Qiu-An Wang; wangqiuan@yahoo.com

Received 11 April 2013; Accepted 19 May 2013

Academic Editors: A. Guijarro, A. Nacci, B. Stanovnik, A. Tarraga, and A. D. Wastowski

Copyright (C) 2013 Jing Zhang et al. This is an open access article distributed under the Creative Commons Attribution License, which permits unrestricted use, distribution, and reproduction in any medium, provided the original work is properly cited.

\begin{abstract}
Chalcones 1 $\sim \mathbf{8}$ and 5-deoxyflavonoids 9 22 were synthesized in good yields by aldol condensation, Algar-Flynn-Oyamada reaction, glycosidation, and deacetylation reaction, respectively, starting from 2-acetyl phenols substituted by methoxy or methoxymethoxy group and appropriately benzaldehydes substituted by methoxy, methoxymethoxy group, or chlorine. Among them, 13 and 17 22 are new compounds. The cytotoxicity bioassays of these chalcones and 5-deoxyflavonoids were screened using the sulforhodamine $\mathrm{B}$ (SRB) protein staining method, and the results showed that compounds $\mathbf{2 , 4 , 5 , 6 , 1 0 , 1 5}$, and 19 exhibited moderate cytotoxicity against the cancer cell line of MDA-MB-231, U251, BGC-823, and B16 in comparison with control drugs (HCPT, Vincristine, and Taxol).
\end{abstract}

\section{Introduction}

Chalcones are a class of natural compounds that widely exist in a variety of plant species. Chemically, they consist of openchain flavonoids in which the two aromatic rings are joined by a three carbon $\alpha, \beta$-unsaturated carbonyl system. The flexible structure of chalcones makes them have a large number of biological activities including antitumor [1], antifungal [2], antiprotozoal [3], antimitotic [4], and antivirus [5] properties. The 5-deoxyflavonoids are also one of the main classes of natural flavonoids; they possess antitumor [6], antiviral, and antibiotic effects [7].

Despite lots of recent impressive reports on chalcones $[8,9]$ and 5-deoxyflavonoids [10], the full potential of such class of compounds is yet to be realized in terms of both more new molecules as drugs and varied biological activity. This situation is largely due to their simple chemical structure and useful template. It has recently become more apparent that most of the important classes of drugs, especially those derived from natural products, are glycosides having a sugar moiety linked to an aglycon through an $O$ - or $C$-glycosidic bond. In our continued efforts to use natural products only as synthetic templates and thereby replace the original plant sources with synthetic ones and investigate structure-activity relationship, herein, we wish to report the synthesis and cytotoxicity bioassays of a series of chalcones $\mathbf{1} \sim \mathbf{8}$ and 5 deoxyflabonoids 9 16 as well as their glycoside derivatives 17 22. Among them, 13 and 17 22 are new compounds.

\section{Results and Discussion}

Scheme 1 outlines the synthesis of chalcones $\mathbf{1} \sim \mathbf{8}$ and 5deoxyflavonoids 9 22, starting from appropriate benzaldehydes 23 27, 33, 34, and acetyl phenols substituted by methoxy or methoxymethoxy, which were purchased or prepared with an improved traditional method in good yields. In the synthesis process, the methoxymethoxy group was chosen to protect the $\mathrm{OH}$ group, because it is stable in basic environment and easy to deprotect. Chalcones 28 32 were prepared by using aldol condensation of appropriate substituted benzaldehydes 23 27, 33, 34, and acetyl phenols in $\mathrm{KOH} / \mathrm{EtOH}$ and deprotection reaction. The aldol condensation was very sensitive to modification of reaction parameters. A significant excess of $\mathrm{KOH}$ (10 15 equiv) was required to force the reaction to completion. Flavonols 9 16 were prepared by classic Algar-Flynn-Oyamada reaction treating the corresponding chalcones with $15 \% \mathrm{H}_{2} \mathrm{O}_{2}$ and $16 \%$ $\mathrm{NaOH}$ (aq) and deprotection reaction.

It is well know that sugar moiety could enhance water solubility and improve the targeting activity of bioactive 


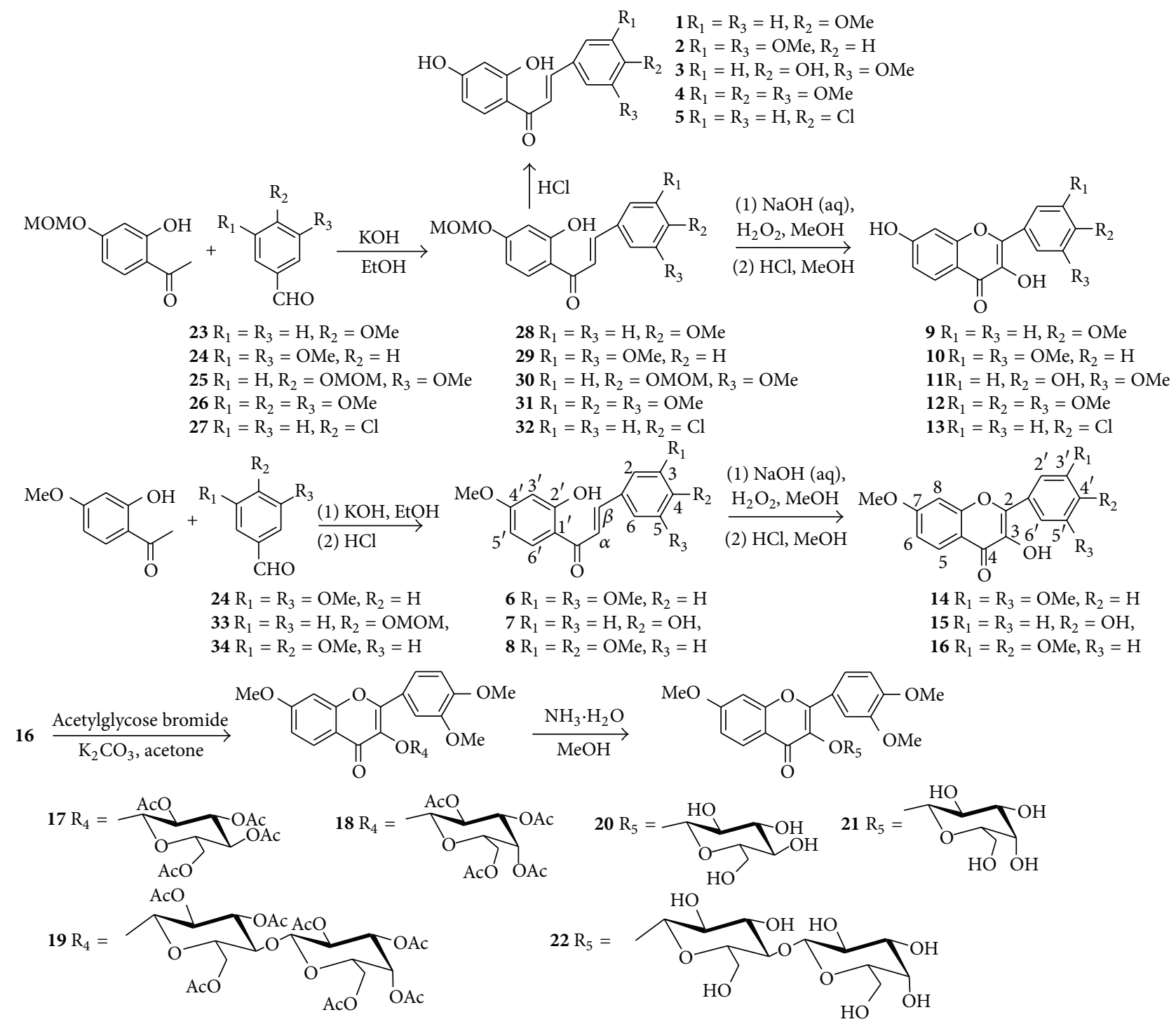

SCHEME 1

molecules [11]. For example, lactose can be recognized by the hepatic asialoglycoprotein receptor (ASGP-R), and ASGP$\mathrm{R}$ localized to liver cells provides an efficient entry point for lactose-modified molecules [12]. The modification of 5deoxyflavonoids with lactose may be possible to specifically target molecules to liver cells, facilitating application of bioactive 5-deoxyflavonoids to the treatment of hepatitis $\mathrm{B}$, hepatitis $\mathrm{C}$, and liver cancer. On the other hand, the largely hydrophobic character of 5-deoxyflavonoids makes it poorly soluble in aqueous media which in some cases limits their therapeutic efficacy, and this has a strong influence on their pharmacokinetic properties. Then, we turned our attention to the introduction of glucosyl, galactosyl, or lactosyl moiety into 5-deoxyflavonoids, and compound $\mathbf{1 6}$ was, respectively, condensed with $\alpha$-acetylglucose bromide, $\alpha$-acetylgalactose bromide, or $\alpha$-acetyllactose bromide in the presence of anhydrous $\mathrm{K}_{2} \mathrm{CO}_{3}$ in a solvent of acetone at room temperature to yield the protected 5-deoxyflavonoids glycosides 17 19.
Careful deprotection of the acetyl groups under mildly alkaline condition $\left(\mathrm{NH}_{3} \cdot \mathrm{H}_{2} \mathrm{O}\right.$ in $\left.\mathrm{MeOH}\right)$ at room temperature afforded the desired three novel 5-deoxyflavonoids-3-O- $\beta$ $\mathrm{D}$-glycosides 20 22. The glycosylation selectively affords $\beta$ products by taking the advantage of 2-OAc neighboring participation effects to secure the 1,2-trans glycosylation of each sugar residue. In the ${ }^{1} \mathrm{H}$ NMR spectra of compounds 20 22, the chemical shift of the $\mathrm{C}_{1}-\mathrm{H}$ in the glycosyl ring appeared downfield $(\delta 5.5 \sim 5.8)$ with a coupling constant $J_{1,2}=7.3 \sim$ $8.0 \mathrm{~Hz}$, which confirmed their $\beta$-anomeric configuration [13].

The 22 designed target chalcones $\mathbf{1} \sim \mathbf{8}$ and 5-deoxyflavonoids 9 22 were exposed to four human cancer cell lines MDA-MB-23 (human breast cancer cell), U251 (human glia cancer cell), BGC-823 (human stomach cancer cell), and B16 (mouse melanoma cell), respectively, for $48 \mathrm{~h}$ using the sulforhodamine B (SRB) protein staining method with the Hydroxycamptothecin (HCPT), Vincristine, and Taxol as positive control. It appeared that these closely related 
molecules displayed a wide range of inhibitory activities against MDA-MB-23, U251, BGC-823, and B16 cancer cells lines at the maximum concentration of $10 \mu \mathrm{g} / \mathrm{mL}$ as shown in Table 1. Compounds 2, 4, 5, 6, 10, 15, and 19 showed moderate cytotoxic activity against four cancer cell lines with $\mathrm{IC}_{50}$ values ranging from 2.37 to $9.71 \mu \mathrm{g} / \mathrm{mL}$.

\section{Experimental}

Melting points were measured on a XRC-1 apparatus and were uncorrected. IR spectra were recorded on a Bruker Tensor-27 spectrometer. ${ }^{1}$ HNMR spectra were recorded on a Bruker AM-500 or Bruker AM-400 instrument, using tetramethylsilane as an internal standard, chemical shifts $(\delta)$ in ppm, and coupling constants $(J)$ in Hz. Mass spectra were determined with ZAB-HS spectrometer by the EI or FAB method. Elemental analyses were carried out on a PerkinElmer 240B microanalyser. All solvents were dried by standard procedures. $\alpha$-Acetylglucose bromide, $\alpha$-acetylgalactose bromide, and $\alpha$-acetyllactose bromide were prepared as described in detail $[14,15]$.

3.1. General Procedure for the Synthesis of Chalcones 1 8. To a stirred solution of $\mathrm{KOH}(9.3 \mathrm{~g}, 165 \mathrm{mmol})$ in $\mathrm{EtOH}(40 \mathrm{~mL})$ cooled in an ice bath was added dropwise a solution of the corresponding acetophenone $(12.9 \mathrm{mmol})$ and aldehyde $(12.9 \mathrm{mmol})$ in $\mathrm{EtOH}(40 \mathrm{~mL})$. The mixture was kept at $0^{\circ} \mathrm{C}$ for $0.5 \mathrm{~h}$ and then room temperature for $22 \mathrm{~h}$. The mixture was poured into ice water $(20 \mathrm{~mL})$, adjusted to $\mathrm{pH} 3 \sim 4$ with $1 \mathrm{~mol} \cdot \mathrm{L}^{-1} \mathrm{HCl}$, filtered, and then recrystallized from $\mathrm{EtOH}$ to obtain the desired products $\mathbf{1} \sim \mathbf{8}$, respectively.

$2^{\prime}, 4^{\prime}$-Hydroxy-4-methoxy chalcone (1): light-yellow needles, yield $91 \%$, and m.p. $178 \sim 180^{\circ} \mathrm{C}$ (lit. [16]: $168 \sim 170^{\circ} \mathrm{C}$ ). ${ }^{1} \mathrm{H}$ NMR (400 MHz, DMSO- $\left.d_{6}\right): \delta 3.83\left(3 \mathrm{H}, \mathrm{s}, \mathrm{OCH}_{3}\right), 6.29$ $\left(1 \mathrm{H}, \mathrm{d}, J=2.4 \mathrm{~Hz}, \mathrm{H}-3^{\prime}\right), 6.42\left(1 \mathrm{H}, \mathrm{dd}, J=9.2,2.4 \mathrm{~Hz}, \mathrm{H}-5^{\prime}\right)$, $7.03(2 \mathrm{H}, \mathrm{d}, J=8.8 \mathrm{~Hz}, \mathrm{H}-3,5), 7.76-7.77(2 \mathrm{H}, \mathrm{d}, J=16.0 \mathrm{~Hz}, \mathrm{H}-$ $\alpha, \beta), 7.78(2 \mathrm{H}, \mathrm{d}, J=8.6 \mathrm{~Hz}), 8.20\left(1 \mathrm{H}, \mathrm{d}, J=9.2 \mathrm{~Hz}, \mathrm{H}-6^{\prime}\right)$, $10.71\left(1 \mathrm{H}, \mathrm{s}, 4^{\prime}-\mathrm{OH}\right)$, and $13.56\left(1 \mathrm{H}, \mathrm{s}, 2^{\prime}-\mathrm{OH}\right)$; Anal. Calcd for $\mathrm{C}_{16} \mathrm{H}_{14} \mathrm{O}_{4}$ : C, 71.10; H, 5.22. Found: C, 71.32; H, 5.17.

$2^{\prime}, 4^{\prime}$-Dihydroxy-3, 5-dimethoxychalcone (2): yellow needles, yield 92\%, and m.p. 96 97 ${ }^{\circ} \mathrm{C}$ (lit. [17]: 97 98 ${ }^{\circ} \mathrm{C}$ ); IR (KBr) $v / \mathrm{cm}^{-1}: 3235,2967,1629,1552,1281,1217,1141,1059$, and 969; ${ }^{1} \mathrm{H}$ NMR (500 MHz, acetone- $\left.d_{6}\right): \delta 3.83\left(6 \mathrm{H}, \mathrm{s}, 2 \mathrm{OCH}_{3}\right)$, $6.37\left(1 \mathrm{H}, \mathrm{d}, J=2.3 \mathrm{~Hz}, \mathrm{H}-3^{\prime}\right), 6.46(1 \mathrm{H}, \mathrm{dd}, J=8.8,2.3 \mathrm{~Hz}, \mathrm{H}-$ $\left.5^{\prime}\right), 6.57(1 \mathrm{H}, \mathrm{s}, \mathrm{H}-4), 7.01(2 \mathrm{H}, \mathrm{s}, \mathrm{H}-6), 7.78(1 \mathrm{H}, \mathrm{d}, J=15.4 \mathrm{~Hz}$, H- $\beta), 7.92(1 \mathrm{H}, \mathrm{d}, J=15.4 \mathrm{~Hz}, \mathrm{H}-\alpha), 8.12(1 \mathrm{H}, \mathrm{d}, J=8.8 \mathrm{~Hz}, \mathrm{H}-$ $\left.6^{\prime}\right), 9.50\left(1 \mathrm{H}, \mathrm{s}, 2^{\prime}-\mathrm{OH}\right)$, and $13.20\left(1 \mathrm{H}, \mathrm{s}, 4^{\prime}-\mathrm{OH}\right) ; \mathrm{MS}\left(\mathrm{FAB}^{+}\right)$ $\mathrm{m} / z: 301[\mathrm{M}+\mathrm{H}]^{+}$.

$2^{\prime}, 4^{\prime}, 4$-Trihydroxy-3-methoxychalcone (3): yellow needles, yield 82\%, and m.p. 192 194 ${ }^{\circ} \mathrm{C}$ (lit. [16]: 192 194 ${ }^{\circ} \mathrm{C}$ ); ${ }^{1} \mathrm{H}$ NMR $\left(400 \mathrm{MHz}, \mathrm{DMSO}-d_{6}\right): \delta 3.88\left(3 \mathrm{H}, \mathrm{s}, \mathrm{OCH}_{3}\right), 6.28(1 \mathrm{H}$, d, $\left.J=2.4 \mathrm{~Hz}, \mathrm{H}-3^{\prime}\right), 6.42\left(1 \mathrm{H}, \mathrm{dd}, J=8.4,2.4 \mathrm{~Hz}, \mathrm{H}-5^{\prime}\right), 6.83$ $\left(1 \mathrm{H}, \mathrm{d}, J=8.4 \mathrm{~Hz}, \mathrm{H}-6^{\prime}\right), 7.28(1 \mathrm{H}, \mathrm{dd}, J=8.8,1.6 \mathrm{~Hz}, \mathrm{H}-6)$, $7.53(1 \mathrm{H}, \mathrm{d}, J=1.6 \mathrm{~Hz}, \mathrm{H}-5), 7.73(1 \mathrm{H}, \mathrm{d}, J=15.2 \mathrm{~Hz}, \mathrm{H}-\beta), 7.79$ $(1 \mathrm{H}, \mathrm{d}, J=15.2 \mathrm{~Hz}, \mathrm{H}-\alpha), 8.20(1 \mathrm{H}, \mathrm{d}, J=8.8 \mathrm{~Hz}, \mathrm{H}-2)$, and 9.74 13.65 (3H, s, OH-2 $\left.2^{\prime}, 4^{\prime}, 4\right)$; $\mathrm{MS}\left(\mathrm{FAB}^{+}\right) m / z: 287[\mathrm{M}+\mathrm{H}]^{+}$.

$2^{\prime}, 4^{\prime}$-Dihydroxy-3,4,5-trimethoxychalcone (4): lightyellow needles, yield 94\%, and m.p. $188 \sim 190^{\circ} \mathrm{C}$ (lit. [18]: $\left.199 \sim 200^{\circ} \mathrm{C}\right)$; IR (KBr) $v / \mathrm{cm}^{-1}$ : 3320, 2912, 2887, 2821, 1619,
TABLE 1: $\mathrm{IC}_{50}$ value $(\mu \mathrm{g} / \mathrm{mL})$ of chalcones and deoxyflavonoids on the cancer cell lines.

\begin{tabular}{lcccc}
\hline Compound & MDA-MB-231 & U251 & BGC-823 & B16 \\
\hline HCPT $^{\text {a }}$ & 1.18 & & & \\
Vincristin $^{\mathrm{b}}$ & & 0.81 & & \\
Taxol $^{\mathrm{c}}$ & & & 0.002 & 0.109 \\
$\mathbf{2}$ & 4.97 & 2.37 & 3.42 & $>10$ \\
$\mathbf{4}$ & $>10$ & $>10$ & 3.87 & 2.88 \\
$\mathbf{5}$ & $>10$ & 6.53 & 3.55 & 2.66 \\
$\mathbf{6}$ & 6.17 & 3.37 & 3.99 & $>10$ \\
$\mathbf{1 0}$ & 4.21 & 8.33 & 3.92 & $>10$ \\
$\mathbf{1 5}$ & 8.68 & 4.95 & 3.71 & $>10$ \\
$\mathbf{1 9}$ & 5.49 & 9.71 & 4.33 & 4.77 \\
\hline a,b,c & Used for positive control. & & &
\end{tabular}

$1575,1492,1455,1365,1320$, and $1182 ;{ }^{1} \mathrm{H}$ NMR $(400 \mathrm{MHz}$, DMSO- $\left.d_{6}\right): \delta 3.91\left(3 \mathrm{H}, \mathrm{s}, \mathrm{OCH}_{3}\right), 3.94\left(6 \mathrm{H}, \mathrm{s}, 2 \mathrm{OCH}_{3}\right)$, $5.79\left(1 \mathrm{H}, \mathrm{s}, 4^{\prime}-\mathrm{OH}\right), 6.44 \sim 6.46\left(2 \mathrm{H}, \mathrm{m}, \mathrm{H}-3^{\prime}, 5^{\prime}\right), 6.87(2 \mathrm{H}, \mathrm{s}$, $\mathrm{H}-2,6), 7.45(1 \mathrm{H}, \mathrm{d}, J=15.2 \mathrm{~Hz}, \mathrm{H}-\alpha), 7.82(1 \mathrm{H}, \mathrm{d}, J=15.2 \mathrm{~Hz}$, $\mathrm{H}-\beta)$, and $13.38\left(1 \mathrm{H}, \mathrm{s}, 2^{\prime}-\mathrm{OH}\right)$; $\mathrm{MS}\left(\mathrm{FAB}^{+}\right) \mathrm{m} / z: 331[\mathrm{M}+\mathrm{H}]^{+}$.

$2^{\prime}, 4^{\prime}$-Dihydroxy-4-chlorochalcone (5): yellow needles, yield $93 \%$, m.p. $154 \sim 156^{\circ} \mathrm{C}$ (lit. [16]: $156 \sim 158^{\circ} \mathrm{C}$ ); ${ }^{1} \mathrm{H}$ NMR $\left(400 \mathrm{MHz}, \mathrm{CDCl}_{3}\right): \delta 6.33\left(1 \mathrm{H}, \mathrm{d}, J=2.4 \mathrm{~Hz}, \mathrm{H}-3^{\prime}\right), 6.43(1 \mathrm{H}$, $\left.\mathrm{dd}, J=8.8,2.0 \mathrm{~Hz}, \mathrm{H}-5^{\prime}\right), 7.54(2 \mathrm{H}, \mathrm{d}, J=8.8 \mathrm{~Hz}, \mathrm{H}-3,5), 7.78$ $(1 \mathrm{H}, \mathrm{d}, J=15.2 \mathrm{~Hz}, \mathrm{H}-\beta), 8.01(1 \mathrm{H}, \mathrm{d}, J=15.2 \mathrm{~Hz}, \mathrm{H}-\alpha), 8.21$ $\left(1 \mathrm{H}, \mathrm{d}, J=9.2 \mathrm{~Hz}, \mathrm{H}-6^{\prime}\right)$, and $10.79\left(1 \mathrm{H}, \mathrm{s}, 4^{\prime}-\mathrm{OH}\right)$; Anal. Calcd for $\mathrm{C}_{15} \mathrm{H}_{11} \mathrm{ClO}_{3}$ : C, 65.58; $\mathrm{H}, 4.04$. Found: $\mathrm{C}, 65.45 ; \mathrm{H}, 4.10$.

$2^{\prime}$-Hydroxy-3,5,7' -trimethoxychalcone (6): yellow needles, yield $83 \%$, and m.p. $147 \sim 149^{\circ} \mathrm{C}$; IR $(\mathrm{KBr}) \nu / \mathrm{cm}^{-1}: 3460$, $3009,2940,2306,1639,1602,1456,1370,1158$, and $839 ;{ }^{1} \mathrm{H}$ $\operatorname{NMR}\left(400 \mathrm{MHz}, \mathrm{CDCl}_{3}\right): \delta 3.85\left(6 \mathrm{H}\right.$, s/each, 3,5- $\left.\mathrm{OCH}_{3}\right), 3.87$ $\left(3 \mathrm{H}, \mathrm{s}, 4^{\prime}-\mathrm{OCH}_{3}\right), 6.48\left(1 \mathrm{H}, \mathrm{d}, J=2.8 \mathrm{~Hz}, \mathrm{H}-3^{\prime}\right), 6.50(1 \mathrm{H}, \mathrm{dd}$, $\left.J=8.4,2.8 \mathrm{~Hz}, \mathrm{H}-5^{\prime}\right), 6.54(1 \mathrm{H}, \mathrm{t}, J=2.4 \mathrm{~Hz}, \mathrm{H}-4), 6.79(2 \mathrm{H}$, d, $J=2.4 \mathrm{~Hz}, \mathrm{H}-2,6), 7.53(1 \mathrm{H}, \mathrm{d}, J=15.6 \mathrm{~Hz}, \mathrm{H}-\beta), 7.80(1 \mathrm{H}$, $\mathrm{d}, J=15.6 \mathrm{~Hz}, \mathrm{H}-\alpha)$, and $7.83\left(1 \mathrm{H}, \mathrm{d}, J=8.4 \mathrm{~Hz}, \mathrm{H}-6^{\prime}\right)$; MS (EI) $m / z: 314\left(\mathrm{M}^{+}, 100\right), 297$ (10), 283 (13), 177 (60), 164(18), and 151(46).

$2^{\prime}$,4-Dihydroxy-4' -methoxy chalcone (7): yellow needles, yield $86 \%$, and m.p. $152 \sim 153^{\circ} \mathrm{C} ;{ }^{1} \mathrm{H}$ NMR $(400 \mathrm{MHz}$, DMSO$\left.d_{6}\right): \delta 3.95\left(3 \mathrm{H}, \mathrm{s}, \mathrm{OCH}_{3}-4^{\prime}\right), 6.28\left(1 \mathrm{H}, \mathrm{d}, J=2.0 \mathrm{~Hz}, \mathrm{H}-3^{\prime}\right)$, $6.41\left(1 \mathrm{H}, \mathrm{dd}, J=9.2,2.4 \mathrm{~Hz}, \mathrm{H}-5^{\prime}\right), 6.84(2 \mathrm{H}, \mathrm{d}, J=8.6 \mathrm{~Hz}$, $\mathrm{H}-3,5), 7.75 \sim 7.77(4 \mathrm{H}, \mathrm{m}, \mathrm{H}-\alpha, \mathrm{H}-\beta, \mathrm{H}-2,6), 8.17(1 \mathrm{H}, \mathrm{d}, J=$ $\left.9.2 \mathrm{~Hz}, \mathrm{H}-6^{\prime}\right), 10.15\left(1 \mathrm{H}, \mathrm{s}, 4^{\prime}-\mathrm{OH}\right), 10.70(1 \mathrm{H}, \mathrm{s}, 4-\mathrm{OH})$, and $13.61\left(1 \mathrm{H}, \mathrm{s}, 2^{\prime}-\mathrm{OH}\right) ; \mathrm{MS}\left(\mathrm{FAB}^{+}\right) m / z: 271[\mathrm{M}+\mathrm{H}]^{+}$.

$2^{\prime}$-Hydroxy-3,4,4' -trimethoxy chalcone (8): yellow needles, yield $74 \%$, and m.p. $145 \sim 147^{\circ} \mathrm{C} ;{ }^{1} \mathrm{H}$ NMR $(400 \mathrm{MHz}$, $\left.\mathrm{CDCl}_{3}\right): \delta 3.95\left(9 \mathrm{H}, \mathrm{s}, 3 \mathrm{OCH}_{3}\right), 6.48\left(1 \mathrm{H}, \mathrm{s}, \mathrm{H}-3^{\prime}\right), 6.51(1 \mathrm{H}$, $\left.\mathrm{d}, J=2.8 \mathrm{~Hz}, \mathrm{H}-5^{\prime}\right), 6.91(1 \mathrm{H}, \mathrm{d}, J=8.4 \mathrm{~Hz}, \mathrm{H}-5), 7.16(1 \mathrm{H}, \mathrm{d}$, $J=1.6 \mathrm{~Hz}, \mathrm{H}-6), 7.25(1 \mathrm{H}, \mathrm{d}, J=1.6 \mathrm{~Hz}, \mathrm{H}-2), 7.44(1 \mathrm{H}, \mathrm{d}, J=$ $15.2 \mathrm{~Hz}, \mathrm{H}-\alpha), 7.84\left(1 \mathrm{H}, \mathrm{s}, \mathrm{H}-6^{\prime}\right), 7.86(1 \mathrm{H}, \mathrm{d}, J=16.8 \mathrm{~Hz}, \mathrm{H}-\beta)$, and $13.54(1 \mathrm{H}, \mathrm{s}, \mathrm{OH}) ; \mathrm{MS}\left(\mathrm{FAB}^{+}\right) \mathrm{m} / z: 315[\mathrm{M}+\mathrm{H}]^{+}$.

3.2. General Procedure for the Synthesis of 5-Deoxyflavonoids 9 16. To a solution of chalcones 6 8, 28 32 $(0.3 \mathrm{mmol})$ in methanol $(5.5 \mathrm{~mL})$ was, respectively, added $16 \% \mathrm{NaOH}(\mathrm{aq})$ $(0.6 \mathrm{~mL}), 15 \% \mathrm{H}_{2} \mathrm{O}_{2}(0.3 \mathrm{~mL})$. The mixture was stirred at 
room temperature for $24 \mathrm{~h}$, adjusted to $\mathrm{pH} 3 \sim 4 \mathrm{with} 1 \mathrm{~mol} \cdot \mathrm{L}^{-1}$ $\mathrm{HCl}$, filtered and then recrystallized from ethanol to obtain the corresponding 5-deoxyflavonols 9 16, respectively.

3,7-Dihydroxy-4'-methoxyflavonol (9): yellow solid, yield: $68 \%$, and m.p. $289 \sim 290^{\circ} \mathrm{C} ;{ }^{1} \mathrm{H}$ NMR $(400 \mathrm{MHz}$, DMSO- $\left.d_{6}\right): \delta 3.83\left(3 \mathrm{H}, \mathrm{s}, \mathrm{OCH}_{3}-4^{\prime}\right), 6.92(1 \mathrm{H}, \mathrm{dd}, J=2.1$, $9.1 \mathrm{~Hz}, \mathrm{H}-6), 6.97(1 \mathrm{H}, \mathrm{d}, J=2.0 \mathrm{~Hz}, \mathrm{H}-8), 7.03(2 \mathrm{H}, \mathrm{d}, J=$ $\left.8.8 \mathrm{~Hz}, \mathrm{H}-3^{\prime}, 5^{\prime}\right), 7.62\left(2 \mathrm{H}, \mathrm{d}, J=8.5 \mathrm{~Hz}, \mathrm{H}-2^{\prime}, 6^{\prime}\right), 9.15(1 \mathrm{H}, \mathrm{s}$, $\mathrm{OH}-7)$, and $10.74(1 \mathrm{H}, \mathrm{s}, \mathrm{OH}-3)$; MS $\left(\mathrm{FAB}^{+}\right) \mathrm{m} / z: 285[\mathrm{M}+$ $\mathrm{H}]^{+}$.

3,7-Dihydroxy-3', $5^{\prime}$-dimethoxyflavonol (10): white solid, yield $93.2 \%$, and m.p. $100 \sim 101^{\circ} \mathrm{C}$; IR $(\mathrm{KBr}) \nu / \mathrm{cm}^{-1}: 3333,3123$, $1741,1617,1562,1274,1204,1156,1064$, and $849 ;{ }^{1} \mathrm{H}$ NMR $\left(500 \mathrm{MHz}, \mathrm{DMSO}-d_{6}\right): \delta 3.80\left(6 \mathrm{H}, \mathrm{s}, 2 \mathrm{OCH}_{3}\right), 6.63(1 \mathrm{H}, \mathrm{s}, \mathrm{H}-$ 8), $6.91(1 \mathrm{H}, \mathrm{d}, J=8.8 \mathrm{~Hz}, \mathrm{H}-6), 6.97\left(1 \mathrm{H}, \mathrm{s}, \mathrm{H}-4^{\prime}\right), 7.33(2 \mathrm{H}, \mathrm{d}$, $\left.J=1.3 \mathrm{~Hz}, \mathrm{H}-2^{\prime}, 6^{\prime}\right), 7.93(1 \mathrm{H}, \mathrm{d}, J=8.8 \mathrm{~Hz}, \mathrm{H}-5), 9.39(1 \mathrm{H}, \mathrm{s}$, 3-OH), and $10.8(1 \mathrm{H}, \mathrm{s}, 7-\mathrm{OH})$; MS $\left(\mathrm{FAB}^{+}\right) \mathrm{m} / z: 315[\mathrm{M}+\mathrm{H}]^{+}$.

$7,4^{\prime}$-Dihydroxy-3' ${ }^{\prime}$-methoxyflavonol (11): yellow solid, yield 93\%, and m.p. $274 \sim 275^{\circ} \mathrm{C}$; ${ }^{1} \mathrm{H}$ NMR (400 MHz, DMSO$\left.d_{6}\right): \delta 3.85\left(3 \mathrm{H}, \mathrm{s}, \mathrm{OCH}_{3}-3^{\prime}\right), 6.91(1 \mathrm{H}, \mathrm{dd}, J=9.2,2.0 \mathrm{~Hz}, \mathrm{H}-6)$, $6.94\left(1 \mathrm{H}, \mathrm{d}, J=8.4 \mathrm{~Hz}, \mathrm{H}-5^{\prime}\right), 6.98(1 \mathrm{H}, \mathrm{d}, J=2.0 \mathrm{~Hz}, \mathrm{H}-8), 7.70$ $\left(1 \mathrm{H}, \mathrm{dd}, J=8.4,2.0 \mathrm{~Hz}, \mathrm{H}-6^{\prime}\right), 7.77\left(1 \mathrm{H}, \mathrm{d}, J=2.0 \mathrm{~Hz}, \mathrm{H}-2^{\prime}\right)$, $7.93(1 \mathrm{H}, \mathrm{d}, J=9.2 \mathrm{~Hz}, \mathrm{H}-5), 9.13,9.67$ (2H, s/each, OH-4' $\left.{ }^{\prime}, 7\right)$, and $10.74(1 \mathrm{H}, \mathrm{s}, \mathrm{OH}-3)$; $\mathrm{MS}\left(\mathrm{FAB}^{+}\right) \mathrm{m} / z: 317[\mathrm{M}+\mathrm{H}]^{+}$.

3,7-Dihydroxy-3' $4^{\prime}, 5^{\prime}$-trimethoxyflavonol (12): yellow solid, yield $85 \%$, and m.p. $120 \sim 122^{\circ} \mathrm{C} ;{ }^{1} \mathrm{H} \mathrm{NMR}(400 \mathrm{MHz}$, DMSO- $\left.d_{6}\right): \delta 3.74\left(3 \mathrm{H}, \mathrm{s}, \mathrm{OCH}_{3}-4^{\prime}\right), 3.86\left(6 \mathrm{H}, \mathrm{s}, \mathrm{OCH}_{3}-5^{\prime}\right.$, $\left.6^{\prime}\right), 6.92(1 \mathrm{H}, \mathrm{d}, J=6.8,2.0 \mathrm{~Hz}, \mathrm{H}-8), 7.02(1 \mathrm{H}, \mathrm{dd}, J=8.8$, $2.0 \mathrm{~Hz}, \mathrm{H}-6), 7.50\left(2 \mathrm{H}, \mathrm{s}, \mathrm{H}-2^{\prime}, 6^{\prime}\right), 7.93(1 \mathrm{H}, \mathrm{d}, J=8.8 \mathrm{~Hz}, \mathrm{H}-5)$, $9.36(1 \mathrm{H}, \mathrm{s}, \mathrm{OH}-7)$, and $10.78(1 \mathrm{H}, \mathrm{s}, \mathrm{OH}-3)$; $\mathrm{MS}\left(\mathrm{FAB}^{+}\right) \mathrm{m} / z$ : $345[\mathrm{M}+\mathrm{H}]^{+}$.

7-Hydroxy-4'-chloroflavonol (13): yellow solid, yield $58 \%$, and m.p. $145 \sim 146^{\circ} \mathrm{C} ;{ }^{1} \mathrm{H}$ NMR $\left(400 \mathrm{MHz}, \mathrm{CDCl}_{3}\right): \delta$ $6.50(1 \mathrm{H}, \mathrm{s}, \mathrm{OH}-3), 6.52 \sim 6.54(2 \mathrm{H}, \mathrm{d}, J=8.4 \mathrm{~Hz}, \mathrm{H}-3,5), 7.09 \sim$ $7.13(2 \mathrm{H}, \mathrm{m}, \mathrm{H}-6,8), 7.60(2 \mathrm{H}, \mathrm{d}, J=8.4 \mathrm{~Hz}, \mathrm{H}-2,6)$, and 8.20 $(1 \mathrm{H}, \mathrm{d}, J=8.8 \mathrm{~Hz}, \mathrm{H}-5)$; Anal. Calcd for $\mathrm{C}_{15} \mathrm{H}_{9} \mathrm{ClO}_{4}$ : C, 62.41; $\mathrm{H}, 3.14$. Found: C, 62.22; H, 3.19.

3-Hydroxy-7,3',5-trimethoxyflavonol (14): yellow needles, yield 49\%, and m.p. 197 198 ${ }^{\circ}$ C; IR (KBr) $v / \mathrm{cm}^{-1}$ : 3449, $3009,1603,1556,1410,1381,1263,1215,1154,1120$, and $829 ;{ }^{1} \mathrm{H}$ NMR (400 MHz, $\left.\mathrm{CDCl}_{3}\right): \delta 3.89\left(6 \mathrm{H}, \mathrm{s}, 3^{\prime}, 5^{\prime}-\mathrm{OCH}_{3}\right), 3.95$ $\left(3 \mathrm{H}, \mathrm{s}, 7-\mathrm{OCH}_{3}\right), 6.58(1 \mathrm{H}, \mathrm{s}, \mathrm{H}-8), 6.96 \sim 7.01(3 \mathrm{H}, \mathrm{m}, \mathrm{H}-$ $\left.6,4^{\prime}, \mathrm{OH}\right), 7.42\left(2 \mathrm{H}, \mathrm{s}, \mathrm{H}-2^{\prime}, 6^{\prime}\right)$, and $8.14(1 \mathrm{H}, \mathrm{d}, J=7.6 \mathrm{~Hz}, \mathrm{H}-$ 5); MS (EI) m/z: 328 (M+ $\left.\mathrm{M}^{+}, 100\right), 313$ (10), 297 (19), 285 (30), 178 (10), 149 (23), 122 (16), and 107 (26).

3,4'-Dihydroxy-7-methoxyflavonol (15): yellow solid, yield 93\%, and m.p. 295 297 ${ }^{\circ} \mathrm{C}$ (lit. [19]: 270 272 ${ }^{\circ} \mathrm{C}$ ); ${ }^{1} \mathrm{H}$ NMR $\left(400 \mathrm{MHz}, \mathrm{DMSO}-d_{6}\right): \delta 3.91\left(3 \mathrm{H}, \mathrm{s}, 7-\mathrm{OCH}_{3}\right), 6.92 \sim$ $6.96\left(2 \mathrm{H}, \mathrm{m}, \mathrm{H}-3^{\prime}, 5^{\prime}\right), 7.03(1 \mathrm{H}, \mathrm{dd}, J=8.8,2.4 \mathrm{~Hz}, \mathrm{H}-6), 7.26$ $(1 \mathrm{H}, \mathrm{d}, J=2.0 \mathrm{~Hz}, \mathrm{H}-8), 7.98(1 \mathrm{H}, \mathrm{d}, J=8.8 \mathrm{~Hz}, \mathrm{H}-5), 8.10(2 \mathrm{H}$, $\left.\mathrm{d}, J=8.8 \mathrm{~Hz}, \mathrm{H}-2^{\prime}, 6^{\prime}\right), 9.23(1 \mathrm{H}, \mathrm{s}, 3-\mathrm{OH})$, and $10.07(1 \mathrm{H}, \mathrm{s}$, 4-OH); MS $\left(\mathrm{FAB}^{+}\right) \mathrm{m} / z: 285[\mathrm{M}+\mathrm{H}]^{+}$.

$3^{\prime}, 4^{\prime}, 7-$ Trimethoxyflavonol (16): yellow solid, yield $86 \%$, and m.p. $178 \sim 180^{\circ} \mathrm{C}$ (lit. [20]: $185^{\circ} \mathrm{C}$ ); ${ }^{1} \mathrm{H}$ NMR (400 MHz, $\left.\mathrm{CDCl}_{3}\right): \delta 4.03 \sim 3.98\left(9 \mathrm{H}\right.$, s/each, $\left.3 \mathrm{OCH}_{3}\right), 6.99(1 \mathrm{H}, \mathrm{d}, J=$ $2.2 \mathrm{~Hz}, \mathrm{H}-6), 7.02(1 \mathrm{H}, \mathrm{d}, J=2.3 \mathrm{~Hz}, \mathrm{H}-8), 7.06(1 \mathrm{H}, \mathrm{s}, \mathrm{OH})$, $7.04\left(1 \mathrm{H}, \mathrm{d}, J=3.3 \mathrm{~Hz}, \mathrm{H}-5^{\prime}\right), 8.17(1 \mathrm{H}, \mathrm{d}, J=8.9 \mathrm{~Hz}, \mathrm{H}-5), 7.89$ $\left(1 \mathrm{H}, \mathrm{dd}, J=8.5,2.0 \mathrm{~Hz}, \mathrm{H}-6^{\prime}\right)$, and $7.86(1 \mathrm{H}, \mathrm{d}, J=1.9 \mathrm{~Hz}, \mathrm{H}-$ $\left.2^{\prime}\right)$; $\mathrm{MS}\left(\mathrm{FAB}^{+}\right) \mathrm{m} / z: 329[\mathrm{M}+\mathrm{H}]^{+}$.

3.3. Synthesis of $3^{\prime}, 4^{\prime}, 7$-Trimethoxyflavonoid-3-O- $\beta$-D-Acetylglucoside (17). Anhydrous $\mathrm{K}_{2} \mathrm{CO}_{3}(150 \mathrm{mg}, 1.09 \mathrm{mmol})$ was added to the mixture of compound $16(70 \mathrm{mg}, 0.2 \mathrm{mmol})$ and dry acetone $(20 \mathrm{~mL})$; then, $\alpha$-acetylglucose bromide $(200 \mathrm{mg}$, $0.49 \mathrm{mmol}$ ) was added to the mixture with stirring. After stirring for $12 \mathrm{~h}$ at room temperature, the acetone was removed under reduced pressure. The residual was chromatographed on silica gel with petroleum ether/ethyl acetate $(3: 1$, volume ratio) as eluent to afford a yellow solid, yield $86 \%$, and m.p. $145 \sim 146^{\circ} \mathrm{C}$; ${ }^{1} \mathrm{H}$ NMR $\left(400 \mathrm{MHz}, \mathrm{CDCl}_{3}\right): \delta 2.12 \sim 1.89(12 \mathrm{H}$, s/each, $\left.\mathrm{COCH}_{3}\right), 3.66 \sim 3.61\left(1 \mathrm{H}, \mathrm{m}, \mathrm{H}-6^{\prime \prime}\right), 3.93(3 \mathrm{H}, \mathrm{s}$, $\left.\mathrm{OCH}_{3}\right), 3.97\left(3 \mathrm{H}, \mathrm{s}, \mathrm{OCH}_{3}\right), 4.03\left(3 \mathrm{H}, \mathrm{s}, \mathrm{OCH}_{3}\right), 5.08(1 \mathrm{H}$, $\left.\mathrm{t}, J=9.6 \mathrm{~Hz}, \mathrm{H}-4^{\prime \prime}\right), 5.23 \sim 5.17\left(1 \mathrm{H}, \mathrm{m}, \mathrm{H}-5^{\prime \prime}\right), 5.28(1 \mathrm{H}, \mathrm{d}$, $\left.J=9.4 \mathrm{~Hz}, \mathrm{H}-3^{\prime \prime}\right), 5.74\left(1 \mathrm{H}, \mathrm{d}, J=7.9 \mathrm{~Hz}, \mathrm{H}-1^{\prime \prime}\right), 6.92(1 \mathrm{H}$, $\left.\mathrm{d}, J=2.2 \mathrm{~Hz}, \mathrm{H}-2^{\prime \prime}\right), 7.01 \sim 6.96(2 \mathrm{H}, \mathrm{m}, \mathrm{H}-6,8), 7.41 \sim 7.29(1 \mathrm{H}$, m, H-5 $\left.5^{\prime}\right), 7.67\left(1 \mathrm{H}, \mathrm{dd}, J=8.6,2.0 \mathrm{~Hz}, \mathrm{H}-6^{\prime}\right), 7.73(1 \mathrm{H}, \mathrm{d}, J=$ $\left.2.0 \mathrm{~Hz}, \mathrm{H}-2^{\prime}\right)$, and $8.12(1 \mathrm{H}, \mathrm{d}, J=8.9 \mathrm{~Hz}, \mathrm{H}-5)$; Anal. Calcd for $\mathrm{C}_{32} \mathrm{H}_{34} \mathrm{O}_{15}$ : C, 58.36; $\mathrm{H}, 5.20$. Found: C, 58.61; $\mathrm{H}, 5.13$.

3.4. Synthesis of $3^{\prime}, 4^{\prime}, 7-$ Trimethoxyflavonoid-3-O- $\beta$-D-Acetylgalactoside (18). Compound 18 was prepared from 16 and $\alpha$-acetylgalactose bromide as described for the preparation of compound $\mathbf{1 7}$ from compound $\mathbf{1 6}$ and $\alpha$-acetylglucose bromide. Yellow solid, yield 74\%, and m.p. $136 \sim 138^{\circ} \mathrm{C} ;{ }^{1} \mathrm{H}$ NMR (400 MHz, $\left.\mathrm{CDCl}_{3}\right): \delta 1.91 \sim 2.16\left(12 \mathrm{H}\right.$, s/each, $\left.\mathrm{COCH}_{3}\right)$, 3.90 3.98 (9H, 3s, $\left.\mathrm{OCH}_{3}\right), 4.07\left(3 \mathrm{H}, \mathrm{s}, \mathrm{H}-2,4^{\prime \prime}, 6^{\prime \prime}\right), 5.15$ $\left(1 \mathrm{H}, \mathrm{dd}, J=10.5,3.5 \mathrm{~Hz}, \mathrm{H}-5^{\prime \prime}\right), 5.39 \sim 5.45\left(2 \mathrm{H}, \mathrm{m}, \mathrm{H}-2^{\prime \prime}, 3^{\prime \prime}\right)$, $5.74\left(1 \mathrm{H}, \mathrm{d}, J=8.0 \mathrm{~Hz}, \mathrm{H}-1^{\prime \prime}\right), 6.91(1 \mathrm{H}, \mathrm{d}, J=2.3 \mathrm{~Hz}, \mathrm{H}-8)$, 6.97 7.02 (2H, m, H-5', 6$), 7.68\left(1 \mathrm{H}, \mathrm{dd}, J=8.6,2.1 \mathrm{~Hz}, \mathrm{H}-6^{\prime}\right)$, $7.96\left(1 \mathrm{H}, \mathrm{d}, J=2.1 \mathrm{~Hz}, \mathrm{H}-2^{\prime}\right)$, and $8.07 \sim 8.13(1 \mathrm{H}, \mathrm{m}, \mathrm{H}-5)$; MS $\left(\mathrm{FAB}^{+}\right) m / z: 659[\mathrm{M}+\mathrm{H}]^{+}$.

3.5. Synthesis of $3^{\prime}, 4^{\prime} 7$-Trimethoxyflavonoid-3-O- $\beta$-D-Acetyllactoside (19). Compound 19 was prepared from 16 and $\alpha$-acetyllactose bromide as described for the preparation of compound $\mathbf{1 7}$ from compound $\mathbf{1 6}$ and $\alpha$-acetylglucose bromide. Yellow solid, yield: $42 \%$, and m.p. $151 \sim 152^{\circ} \mathrm{C}$. IR (KBr) $v / \mathrm{cm}^{-1}: 3548,3414,3139,1749,1637,1618,1514,1400$, $1237,1135,1063,956,838,780,620,541$, and $484 .{ }^{1} \mathrm{H}$ NMR $\left(400 \mathrm{MHz} \mathrm{CDCl}_{3}\right): \delta 1.85 \sim 2.15\left(21 \mathrm{H}\right.$, s/each, $\left.\mathrm{COCH}_{3}\right), 3.53 \sim$ 3.55 (1H, m, H-sugar), 3.77 3.92 (3H, m, H-sugar), 3.93 4.01 $\left(9 \mathrm{H}\right.$, s/each, $\left.3 \mathrm{OCH}_{3}\right), 4.05(1 \mathrm{H}, \mathrm{d}, J=7.5 \mathrm{~Hz}, \mathrm{H}$-sugar $), 4.08$ $(1 \mathrm{H}, \mathrm{d}, J=7.5 \mathrm{~Hz}, \mathrm{H}$-sugar $), 4.14(1 \mathrm{H}, \mathrm{dd}, J=6.2,11.1 \mathrm{~Hz}, \mathrm{H}-$ sugar), $4.28(1 \mathrm{H}, \mathrm{dd}, J=12.0,2.0 \mathrm{~Hz}, \mathrm{H}$-sugar $), 4.43(1 \mathrm{H}, \mathrm{d}$, $\left.J=7.9 \mathrm{~Hz}, \mathrm{H}_{-1}{ }^{\prime \prime \prime}\right), 4.92(1 \mathrm{H}, \mathrm{dd}, J=10.4,3.4 \mathrm{~Hz}, \mathrm{H}$-sugar $)$, $5.05 \sim 5.13$ (2H, m, H-sugar), 5.25 ( $1 \mathrm{H}, \mathrm{t}, J=9.3 \mathrm{~Hz}, \mathrm{H}$-sugar), $5.33(1 \mathrm{H}, \mathrm{d}, J=2.5 \mathrm{~Hz}, \mathrm{H}$-sugar $), 5.65(1 \mathrm{H}, \mathrm{d}, J=7.9 \mathrm{~Hz}, \mathrm{H}-$ $\left.1^{\prime \prime}\right), 6.91(1 \mathrm{H}, \mathrm{d}, J=2.3 \mathrm{~Hz}, \mathrm{H}-6), 6.95 \sim 7.01\left(2 \mathrm{H}, \mathrm{m}, \mathrm{H}-5^{\prime}, 8\right)$, $7.62 \sim 7.68\left(2 \mathrm{H}, \mathrm{m}, \mathrm{H}-2^{\prime}, 6^{\prime}\right)$, and $8.11(1 \mathrm{H}, \mathrm{d}, J=8.9 \mathrm{~Hz}, \mathrm{H}-5)$; $\mathrm{MS}\left(\mathrm{FAB}^{+}\right) m / z: 947[\mathrm{M}+\mathrm{H}]^{+}$.

3.6. Synthesis of $3^{\prime}, 4^{\prime}, 7-T r i m e t h o x y f l a v o n o i d-3-O-\beta-D-G l u c o-$ side (20). Compound $17(15 \mathrm{mg}, 22.7 \mathrm{mmol})$ was added to a solution of $30 \% \mathrm{NH}_{3} \cdot \mathrm{H}_{2} \mathrm{O}(0.5 \mathrm{~mL})$ in $\mathrm{CH}_{3} \mathrm{OH}(3 \mathrm{~mL})$ with stirring. After stirring for $6 \mathrm{~h}$ at room temperature, the solvent 
was removed under reduced pressure. The residual was chromatographed on silica gel with ethyl acetate/EtOH $(1: 1$, volume ratio) as eluent to afford a light-yellow solid $70 \mathrm{mg}$, yield $79 \%$, and m.p. $110 \sim 111^{\circ} \mathrm{C} .{ }^{1} \mathrm{H}$ NMR (400 MHz, DMSO$\left.d_{6}\right): \delta 3.11 \sim 3.28\left(4 \mathrm{H}, \mathrm{m}, \mathrm{H}-3^{\prime \prime}, 4^{\prime \prime}, 5^{\prime \prime}, 6^{\prime \prime}\right), 3.37 \sim 3.43(1 \mathrm{H}, \mathrm{m}$, $\left.\mathrm{H}-2^{\prime \prime}\right), 3.57\left(1 \mathrm{H}, \mathrm{dd}, J=11.4,5.6 \mathrm{~Hz}, \mathrm{H}-6^{\prime \prime}\right), 3.85 \sim 3.92(9 \mathrm{H}$, s/each, $\left.\mathrm{OCH}_{3}\right), 4.38\left(1 \mathrm{H}, \mathrm{t}, J=5.4 \mathrm{~Hz}, \mathrm{OH}-6^{\prime \prime}\right), 4.96(1 \mathrm{H}, \mathrm{d}$, $\left.J=4.1 \mathrm{~Hz}, \mathrm{OH}-4^{\prime \prime}\right), 5.09\left(1 \mathrm{H}, \mathrm{d}, J=4.6 \mathrm{~Hz}, \mathrm{OH}-3^{\prime \prime}\right), 5.43(1 \mathrm{H}$, d, $\left.J=4.2 \mathrm{~Hz}, \mathrm{OH}-2^{\prime \prime}\right), 5.65\left(1 \mathrm{H}, \mathrm{d}, J=7.3 \mathrm{~Hz}, \mathrm{H}-1^{\prime \prime}\right), 7.08(1 \mathrm{H}$, dd, $J=8.9,2.3 \mathrm{~Hz}, \mathrm{H}-6), 7.12(1 \mathrm{H}, \mathrm{d}, J=8.7 \mathrm{~Hz}, \mathrm{H}-8), 7.27(1 \mathrm{H}$, d, $\left.J=2.3 \mathrm{~Hz}, \mathrm{H}-5^{\prime}\right), 7.68\left(1 \mathrm{H}, \mathrm{dd}, J=8.5,1.9 \mathrm{~Hz}, \mathrm{H}-6^{\prime}\right), 7.96(1 \mathrm{H}$, $\left.\mathrm{d}, J=1.9 \mathrm{~Hz}, \mathrm{H}-2^{\prime}\right)$, and $7.98(1 \mathrm{H}, \mathrm{d}, J=8.9 \mathrm{~Hz}, \mathrm{H}-5)$; Anal. Calcd for $\mathrm{C}_{24} \mathrm{H}_{26} \mathrm{O}_{11}$ : C, 58.77; $\mathrm{H}, 5.34$. Found: $\mathrm{C}, 58.96 ; \mathrm{H}$, 5.28 .

3.7. Synthesis of $3^{\prime}, 4^{\prime}, 7$-Trimethoxyflavonoid-3-O- $\beta$-D-Galactoside (21). Compound 21 was prepared from compound $\mathbf{1 8}$ as described for the preparation of compound $\mathbf{2 0}$ from compound 17. Light-yellow solid, yield 67\%, and m.p. 135 $137^{\circ} \mathrm{C}$. IR (KBr) $v / \mathrm{cm}^{-1}: 3413,3233,1618,1518,1446,1399,1270$, $1206,1077,1017,883,776,620$, and $482 ;{ }^{1} \mathrm{H}$ NMR $(400 \mathrm{MHz}$, DMSO- $\left.d_{6}\right): \delta 3.39 \sim 3.46\left(3 \mathrm{H}, \mathrm{m}, \mathrm{H}-2^{\prime}, 5^{\prime \prime}, 6^{\prime \prime}\right), 3.49(1 \mathrm{H}, \mathrm{dd}$, $\left.J=9.7,4.6 \mathrm{~Hz}, \mathrm{H}-3^{\prime \prime}\right), 3.54 \sim 3.61\left(1 \mathrm{H}, \mathrm{m}, \mathrm{H}-4^{\prime \prime}\right), 3.68(1 \mathrm{H}, \mathrm{t}$, $\left.J=3.4 \mathrm{~Hz}, \mathrm{H}-2^{\prime \prime}\right), 3.85\left(6 \mathrm{H}, \mathrm{s}, \mathrm{OCH}_{3}\right), 3.92\left(3 \mathrm{H}, \mathrm{s}, \mathrm{OCH}_{3}\right)$, $4.50\left(1 \mathrm{H}, \mathrm{d}, J=5.3 \mathrm{~Hz}, \mathrm{OH}-6^{\prime \prime}\right), 4.54(1 \mathrm{H}, \mathrm{d}, J=3.7 \mathrm{~Hz}, \mathrm{OH}-$ $\left.2^{\prime \prime}\right), 4.91\left(1 \mathrm{H}, \mathrm{d}, J=5.6 \mathrm{~Hz}, \mathrm{OH}-4^{\prime \prime}\right), 5.28(1 \mathrm{H}, \mathrm{d}, J=4.3 \mathrm{~Hz}$, $\left.\mathrm{OH}-3^{\prime \prime}\right), 5.57\left(1 \mathrm{H}, \mathrm{d}, J=7.7 \mathrm{~Hz}, \mathrm{H}-1^{\prime \prime}\right), 7.09(2 \mathrm{H}, \mathrm{dd}, J=13.7$, $5.4 \mathrm{~Hz}, \mathrm{H}-6,8), 7.28\left(1 \mathrm{H}, \mathrm{d}, J=2.2 \mathrm{~Hz}, \mathrm{H}-5^{\prime}\right), 7.68(1 \mathrm{H}, \mathrm{dd}, J=$ $\left.8.5,1.9 \mathrm{~Hz}, \mathrm{H}-6^{\prime}\right), 7.98\left(1 \mathrm{H}, \mathrm{d}, J=8.9 \mathrm{~Hz}, \mathrm{H}-2^{\prime}\right)$, and $8.04(1 \mathrm{H}$, d, $J=1.8 \mathrm{~Hz}, \mathrm{H}-5)$; Anal. Calcd for $\mathrm{C}_{24} \mathrm{H}_{26} \mathrm{O}_{11}$ : C, 58.77; $\mathrm{H}$, 5.34. Found: C, 58.54; H, 5.26.

3.8. Synthesis of $3^{\prime}, 4^{\prime}, 7-T r i m e t h o x y f l a v o n o i d-3-O-\beta$-D-Lactoside (22). Compound 22 was prepared from compound 19 as described for the preparation of compound $\mathbf{2 0}$ from compound 17. Light-yellow solid, yield $82 \%$, and m.p. $>200^{\circ} \mathrm{C}$. IR $(\mathrm{KBr}) \nu / \mathrm{cm}^{-1}: 3413,3231,1618,1588,1553,1518,1447,1399$, $1260,1223,1153,1122,1091,1040,1018,958,895,863,829,780$, $675,618,541$, and $484 ;{ }^{1} \mathrm{H}$ NMR $\left(400 \mathrm{MHz}, \mathrm{DMSO}-d_{6}\right): \delta$ $3.38(2 \mathrm{H}, \mathrm{s}, \mathrm{H}$-sugar $), 3.46(3 \mathrm{H}, \mathrm{d}, J=7.1 \mathrm{~Hz}, \mathrm{H}$-sugar $), 3.49 \sim$ $3.59(3 \mathrm{H}, \mathrm{m}, \mathrm{H}$-sugar), $3.61(2 \mathrm{H}, \mathrm{s}, \mathrm{H}$-sugar $), 3.85 \sim 3.92(9 \mathrm{H}$, s/each, $\left.\mathrm{OCH}_{3}\right), 4.23(1 \mathrm{H}, \mathrm{d}, J=7.2 \mathrm{~Hz}, \mathrm{H}$-sugar $), 4.43(2 \mathrm{H}$, t, $J=5.6 \mathrm{~Hz}, \mathrm{OH}$-sugar), $4.52(1 \mathrm{H}, \mathrm{d}, J=4.6 \mathrm{~Hz}, \mathrm{OH}$-sugar $)$, $4.68(1 \mathrm{H}, \mathrm{t}, J=5.1 \mathrm{~Hz}, \mathrm{OH}$-sugar $), 4.78(1 \mathrm{H}, \mathrm{d}, J=5.3 \mathrm{~Hz}, \mathrm{OH}-$ sugar), $4.81(1 \mathrm{H}, \mathrm{d}, J=1.7 \mathrm{~Hz}, \mathrm{OH}$-sugar $), 5.09(1 \mathrm{H}, \mathrm{d}, J=$ $4.3 \mathrm{~Hz}, \mathrm{OH}$-sugar), $5.56\left(1 \mathrm{H}, \mathrm{d}, J=6.3 \mathrm{~Hz}, \mathrm{H}-1^{\prime \prime \prime}\right), 5.67(1 \mathrm{H}$, $\left.\mathrm{d}, J=7.8 \mathrm{~Hz}, \mathrm{H}-1^{\prime \prime}\right), 7.08(1 \mathrm{H}, \mathrm{dd}, J=2.4,8.9 \mathrm{~Hz}, \mathrm{H}-6), 7.13$ $(1 \mathrm{H}, \mathrm{d}, J=8.7 \mathrm{~Hz}, \mathrm{H}-8), 7.29\left(1 \mathrm{H}, \mathrm{d}, J=2.3 \mathrm{~Hz}, \mathrm{H}-5^{\prime}\right), 7.71(1 \mathrm{H}$, $\left.\mathrm{dd}, J=8.6,2.0 \mathrm{~Hz}, \mathrm{H}-6^{\prime}\right), 7.92\left(1 \mathrm{H}, \mathrm{d}, J=2.1 \mathrm{~Hz}, \mathrm{H}-2^{\prime}\right)$, and $7.99(1 \mathrm{H}, \mathrm{d}, J=8.9 \mathrm{~Hz}, \mathrm{H}-5)$; Anal. Calcd for $\mathrm{C}_{30} \mathrm{H}_{36} \mathrm{O}_{16}: \mathrm{C}$, 55.21; H, 5.56. Found: C, 55.49; H, 5.47.

3.9. In Vitro Cytotoxic Activity Evaluation by SRB Assay. The cytotoxic activity of the chalcones and 5-deoxyflavonoid was evaluated against MDA-MB-231, U251, BGC-823, and B16 tumor cells. MDA-MB-231, U251, BGC-823, and B16 cells were maintained in RPMI-1640 medium supplement with $10 \%$ heat inactivated fetal bovine serum (FBS) and incubated at $37^{\circ} \mathrm{C}$ in a $5 \% \mathrm{CO}_{2}$ humidified atmosphere. In order to maintain the cells in log phase cellular suspension, aliquots were refed with fresh RPMI-1640 medium two or three times per week. The stock solutions of the tested compounds were freshly resolved in DMSO and consequently diluted in RPMI1640. At the final dilutions, the obtained concentration of the solvent never exceeded $0.5 \%$.

The cytotoxic activity was measured in vitro using the SRB colorimetric assay. Cells were inoculated in 96-well microtiter plate $\left(10^{4}\right.$ cells/well) for $24 \mathrm{~h}$ before treatment with the compound(s) to allow attachment of the cell to the wall of the plate. Test compounds were dissolved in DMSO and diluted with saline to the appropriate volume. Different concentrations of the compound under test $(0.1,2.5,5$ and $10 \mu \mathrm{g} / \mathrm{mL}$ ) were added to the cell monolayer. Triplicates were prepared for each individual dose. Monolayer cells were incubated with the compound(s) for $48 \mathrm{~h}$, at $37^{\circ} \mathrm{C}$, and in atmosphere of $5 \% \mathrm{CO}_{2}$. After $48 \mathrm{~h}$, cells were fixed, washed, and stained for $30 \mathrm{~min}$ with $0.4 \%(\mathrm{w} / \mathrm{v}) \mathrm{SRB}$ dissolved in $1 \%$ acetic acid. Unbound dye was removed by four washes with $1 \%$ acetic acid, and attached stain was recovered with Tris-EDTA buffer. Color intensity was measured in an ELISA reader. The relation between survival curve for cancer cell lines after the specified time. The concentration required for $50 \%$ inhibition of cell viability $\left(\mathrm{IC}_{50}\right)$ was calculated.

\section{Acknowledgments}

This work was supported by the Personal Training Funds in National Basic Science of China (J1103312/J0104) and the Project of Science of Department of Education of Hunan Province (10B012).

\section{References}

[1] S. K. Kumar, E. Hager, C. Pettit, H. Gurulingappa, N. E. Davidson, and S. R. Khan, "Design, synthesis, and evaluation of novel boronic-chalcone derivatives as antitumor agents," Journal of Medicinal Chemistry, vol. 46, no. 14, pp. 2813-2815, 2003.

[2] A. Lopez, D. S. Ming, and G. H. Neil Towers, "Antifungal activity of benzoic acid derivatives from piper lanceaefolium," Journal of Natural Products, vol. 65, no. 1, pp. 62-64, 2002.

[3] M. M. Salem and K. A. Werbovetz, "Antiprotozoal compounds from Psorothamnus polydenius," Journal of Natural Products, vol. 68, no. 1, pp. 108-111, 2005.

[4] M. L. Edwards, D. M. Stemerick, and P. S. Sunkara, "Chalcones: a new class of antimitotic agents," Journal of Medicinal Chemistry, vol. 33, no. 7, pp. 1948-1954, 1990.

[5] J. H. Wu, X. H. Wang, Y. H. Yi, and K. H. Lee, "Anti-AIDS agents 54. A potent anti-HIV chalcone and flavonoids from genus Desmos," Bioorganic \& Medicinal Chemistry Letters, vol. 13, no. 10, pp. 1813-1815, 2003.

[6] L.-C. Lin, C.-T. Chiou, and J. J. Cheng, "5-Deoxyflavones with cytotoxic activity from Mimosa diplotricha," Journal of Natural Products, vol. 74, no. 9, pp. 2001-2004, 2001.

[7] P. H. Nguyen, T. T. Dao, J. Kim, D. T. Phong, J. T. Ndinteh, and W. K. O. Mbafaor, "New 5-deoxyflavonoids and their inhibitory effects on protein tyrosine phosphatase 1B (PTP1B) activity," Bioorganic \& Medicinal Chemistry, vol. 19, no. 11, pp. 3378-3383, 2011. 
[8] J. Deng, T. Sanchez, L. Q. Al-Mawsawi et al., "Discovery of structurally diverse HIV-1 integrase inhibitors based on a chalcone pharmacophore," Bioorganic \& Medicinal Chemistry, vol. 15, no. 14, pp. 4985-5002, 2007.

[9] H. P. Avila, E. D. F. A. Smania, F. D. Monache, and A. Smânia Jr., "Structure-activity relationship of antibacterial chalcones," Bioorganic \& Medicinal Chemistry, vol. 16, no. 22, pp. 97909794, 2008.

[10] C. Chiruta, D. Schubert, R. Dargusch, and P. Maher, "Chemical modification of the multitarget neuroprotective compound fisetin," Journal of Medicinal Chemistry, vol. 55, no. 1, pp. 378389, 2012.

[11] L. Wells, K. Vosseller, and G. W. Hart, "Glycosylation of nucleocytoplasmic proteins: signal transduction and O-GlcNAc," Science, vol. 291, no. 5512, pp. 2376-2378, 2001.

[12] X. Zhang, C. G. Simmons, and D. R. Coreg, "Liver cell specific targeting of peptide nucleic acid oligomers," Bioorganic \& Medicinal Chemistry Letters, vol. 11, no. 10, pp. 1269-1272, 2001.

[13] Z. Wu, Z. Y. Liang, W. Li, Y. M. Ren, and Q. A. Wang, "Synthesis of naturally occurring neolignans demethylnitidanin, herpetol and salvinal as well as their glycosyl derivatives," Chemical Research in Chinese Universities, vol. 27, no. 6, pp. 949-954, 2011.

[14] B. S. Furniss, A. J. Hannaford, and P. W. G. A. R. Smith, Textbook of Practical Organic Chemistry, John Wiley \& Sons, New York, NY, USA, 5th edition, 1989.

[15] J. Zhao, Z. P. Zhang, H. S. Chen, X. Q. Zhang, and X. H. Chen, "Synthesis of baicalin derivatives and evaluation of their antihuman immunodeficiency virus(HIV-1) activity," Acta Pharmacologica Sinica, vol. 33, p. 22, 1998.

[16] L. P. Guan, X. M. Yin, H. M. Quan, and Z. S. Quan, "Synthesis of hydroxylated chalcones and related derivatives," Chinese Journal of Organic Chemistry, vol. 24, no. 10, pp. 1274-1277, 2004.

[17] U. Anthoni, E. D. Rosalba, P. H. Nielsen, and G. Christophersen, "Huazhongilexone is not $3^{\prime}, 5,5^{\prime}, 7$-tetrahydroxyflavanone. Preparation of $3^{\prime}, 5^{\prime}$-dimethoxy-5,7-dihydroxyflavanone," Acta Chemica Scandinavica, vol. 52, no. 10, pp. 1243-1246, 1998.

[18] M. P. Neves, S. Cravo, R. T. Lima et al., "Solid-phase synthesis of $2 /$-hydroxychalcones. Effects on cell growth inhibition, cell cycle and apoptosis of human tumor cell lines," Bioorganic \& Medicinal Chemistry, vol. 20, no. 1, pp. 25-33, 2012.

[19] T. H. Simpson and L. Garden, "905. Chelate systems. Part I," Journal of the Chemical Society, pp. 4638-4644, 1952.

[20] T. Oyamada, "A new general method for the synthesis of flavonol derivatives," The Chemical Society of Japan, vol. 55, pp. 1256-1261, 1934. 

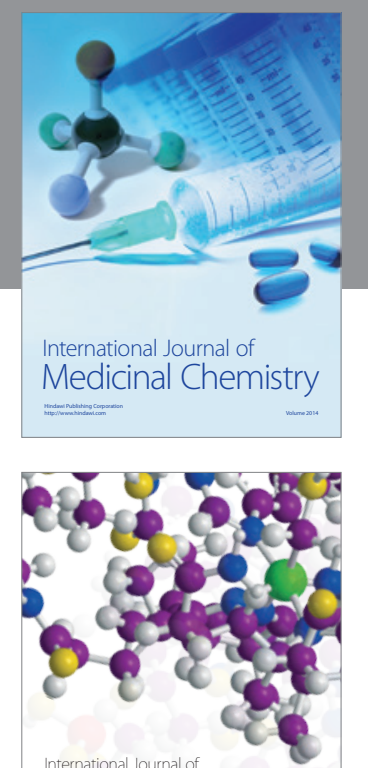

\section{Carbohydrate} Chemistry

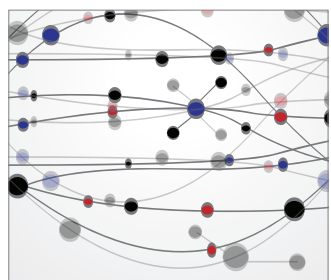

The Scientific World Journal
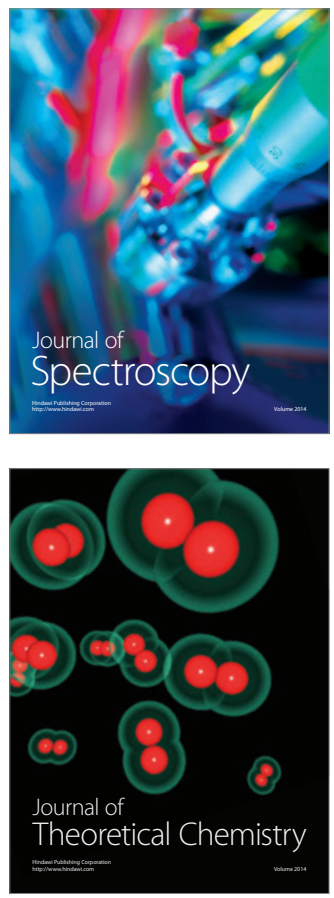
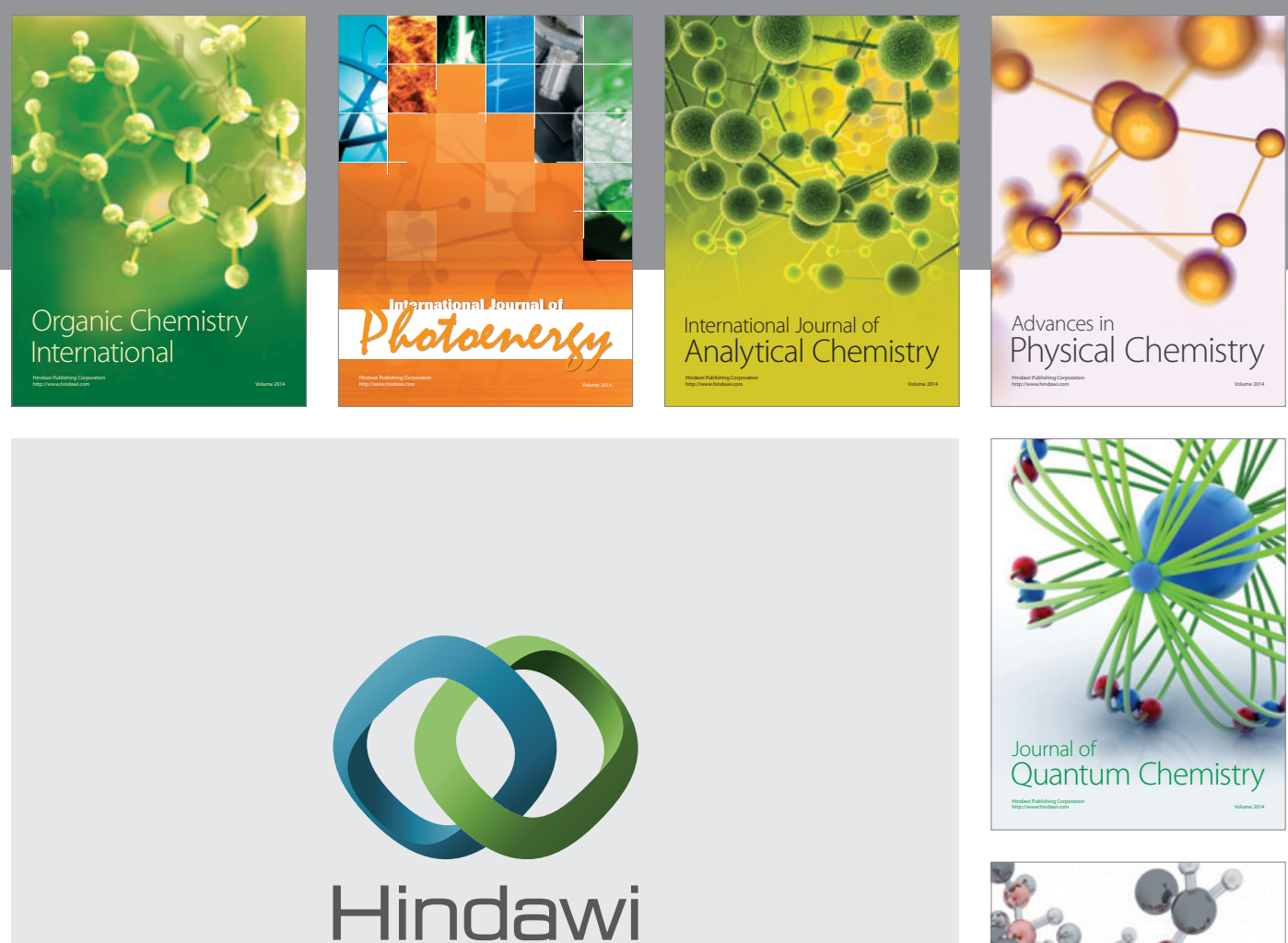

Submit your manuscripts at

http://www.hindawi.com

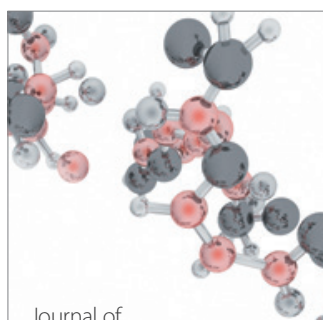

Analytical Methods

in Chemistry

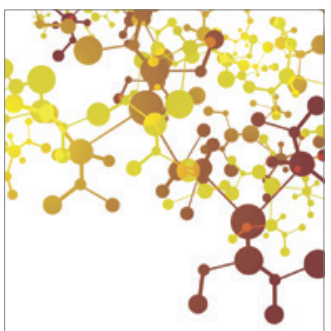

Journal of

Applied Chemistry

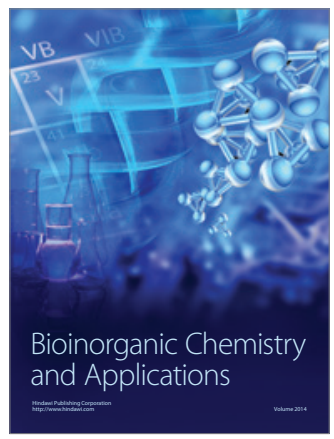

Inorganic Chemistry
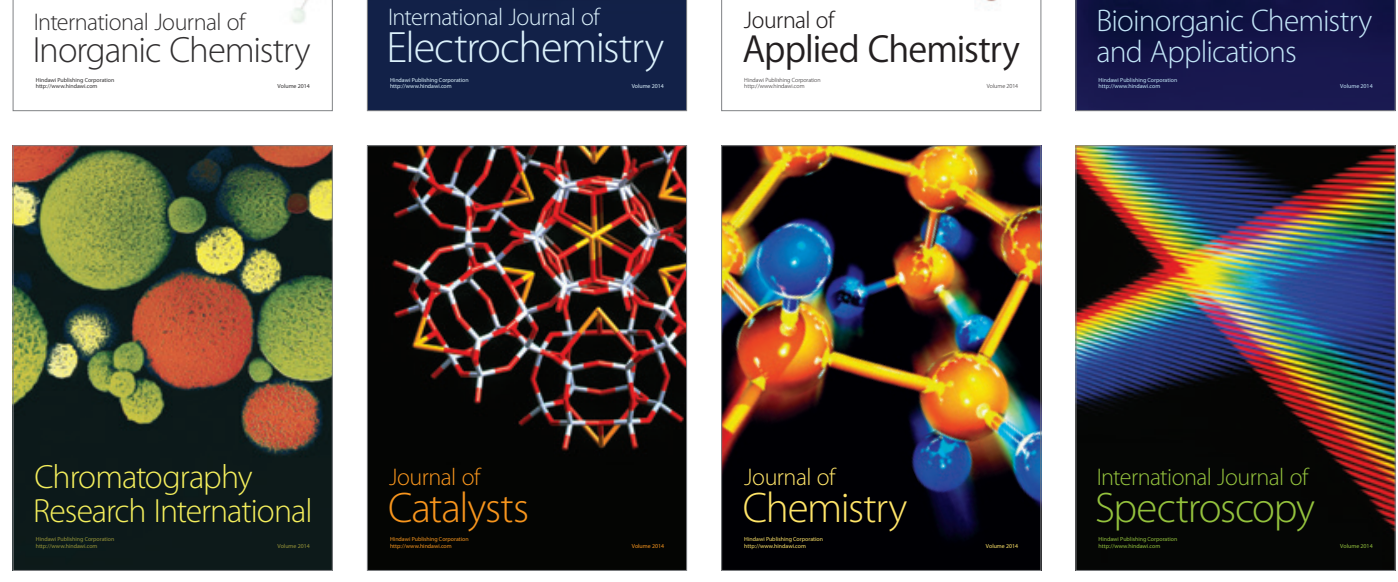